Article

\title{
Repurposing Heparin as Antimalarial: Evaluation of Multiple Modifications Toward In Vivo Application
}

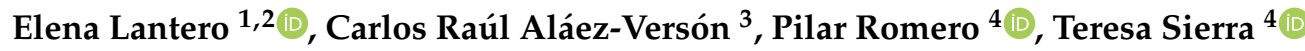 \\ and Xavier Fernàndez-Busquets $1,2,5, * \mathbb{D}$ \\ 1 Barcelona Institute for Global Health (ISGlobal, Hospital Clínic-Universitat de Barcelona), Rosselló 149-153, \\ ES-08036 Barcelona, Spain; elantero@ibecbarcelona.eu \\ 2 Nanomalaria Group, Institute for Bioengineering of Catalonia (IBEC), The Barcelona Institute of Science and \\ Technology, Baldiri Reixac 10-12, ES-08028 Barcelona, Spain \\ 3 BIOIBERICA S.A.U., Polígon Industrial “Mas Puigvert”, Ctra. N-II, km. 680.6, ES-08389 Palafolls, Spain; \\ cralaez@bioiberica.com \\ 4 Instituto de Nanociencia y Materiales de Aragón (INMA), University of Zaragoza-CSIC, Pedro Cerbuna 12, \\ ES-50009 Zaragoza, Spain; promero@unizar.es (P.R.); tsierra@unizar.es (T.S.) \\ 5 Nanoscience and Nanotechnology Institute (IN2UB), University of Barcelona, Martí i Franquès 1, \\ ES-08028 Barcelona, Spain \\ * Correspondence: xfernandez_busquets@ub.edu; Tel.: +34-93-227-5400 (ext. 4581)
}

Received: 30 June 2020; Accepted: 7 August 2020; Published: 29 August 2020

check for updates

\begin{abstract}
Heparin is a promising antimalarial drug due to its activity in inhibiting Plasmodium invasion of red blood cells and to the lack of resistance evolution by the parasite against it, but its potent anticoagulant activity is preventing the advance of heparin along the clinical pipeline. We have determined, in in vitro Plasmodium falciparum cultures, the antimalarial activity of heparin-derived structures of different origins and sizes, to obtain formulations having a good balance of in vitro safety (neither cytotoxic nor hemolytic), low anticoagulant activity ( $\leq 23 \mathrm{IU} / \mathrm{mL}$ according to activated partial thromboplastin time assays), and not too low antimalarial activity (IC50 at least around $100 \mu \mathrm{g} / \mathrm{mL}$ ). This led to the selection of five chemically modified heparins according to the parameters explored, i.e., chain length, sulfation degree and position, and glycol-split, and whose in vivo toxicity indicated their safety for mice up to an intravenous dose of $320 \mathrm{mg} / \mathrm{kg}$. The in vivo antimalarial activity of the selected formulations was poor as a consequence of their short blood half-life. The covalent crosslinking of heparin onto the surface of polyethylene glycol-containing liposomes did not affect its antimalarial activity in vitro and provided higher initial plasma concentrations, although it did not increase mean circulation time. Finding a suitable nanocarrier to impart long blood residence times to the modified heparins described here will be the next step toward new heparin-based antimalarial strategies.
\end{abstract}

Keywords: malaria; heparin; Plasmodium falciparum

\section{Introduction}

Despite being preventable and treatable, malaria continues to have a devastating impact on people's health and livelihoods around the world. According to the last World Malaria Report [1], around 228 million cases of malaria occurred globally in 2018 (up from 216 million in 2016), and the disease led to an estimated 405,000 deaths, mostly children under five years of age in sub-Saharan Africa. Although there were an estimated 11 million fewer malaria cases in 2018 than in 2010, data for the period 2015-2018 highlight that no significant progress in reducing global malaria incidence was made in this timeframe. In the Greater Mekong subregion, there is now Plasmodium falciparum resistance to artemisinin and other drugs, which is leading to treatment failure. Resistance to antimalarial drugs has 
had a significant impact on the cost of global malaria control, as new drugs have had to be developed to replace those that have become ineffective. In this context, the application of the 3 Rs of drug development (rescue, repurpose, reposition) to previously discarded compounds is an interesting strategy to return value to potential treatments in decline or on hold.

Red blood cells (RBCs) infected with mature stages of the malaria parasite bind to the endothelial cells in the capillaries of tissues in a phenomenon known as sequestration, which allows Plasmodium to replicate while evading splenic clearance [2]. Plasmodium-infected RBCs (pRBCs) can also adhere to non-infected erythrocytes giving rise to rosettes, and they can form clumps through platelet-mediated binding to other pRBCs [3]. These events, which may lead to occlusion of the microvasculature, are thought to play a major role in the fatal outcome of severe malaria. Because the blood-stage infection is responsible for all symptoms and pathologies of malaria, pRBCs have traditionally been a main chemotherapeutic target [4]. One of the main pRBC-binding molecules are glycosaminoglycans (GAGs), a family of ubiquitous polysaccharides, some of whose members count among the most negatively charged natural polymers. Binding to the GAG chondroitin 4-sulfate (CSA) is thought to cause pRBC sequestration in the placenta, which has been linked to the severe disease outcome of pregnancy-associated malaria [5]. Heparan sulfate (HS), or a HS-like molecule exposed on RBCs, is the ligand responsible for rosetting [6], and is also targeted by the circumsporozoite protein in the sporozoite attachment to hepatocytes during the primary stage of malaria infection in the liver $[7,8]$. GAG-based therapies against malaria have been proposed in the wake of the results from different assays showing that soluble CSA, heparin, HS, heparin/HS derivatives, and other sulfated glycoconjugates can inhibit pRBC sequestration, disrupt rosettes, and block sporozoite adhesion to hepatocytes [9-11]. Heparin had actually been used in the treatment of severe malaria [12], but it was abandoned because of its strong anticoagulant action, with side effects such as intracranial bleeding. However, depolymerized heparin lacking anticoagulant activity has been found to disrupt rosette formation and $\mathrm{pRBC}$ cytoadherence in vitro and in vivo in animal models and in fresh parasite isolates [13].

Heparin has also a direct antimalarial activity on the pathogen, which operates through the inhibition of parasite invasion of RBCs [14], mainly by interaction with the merozoite surface protein 1 (MSP1) [15] involved in the initial contact and reorientation of the Plasmodium cell pursuing invasion [16]. Single-molecule force spectroscopy data have revealed a complete specificity of adhesion of heparin to late form pRBCs (schizonts) vs. RBCs, with a binding strength matching that of antibody-antigen interactions [17]. Confocal fluorescence analysis showed that when added to living pRBC cultures fluorescein-labeled heparin enters late schizonts about to burst and in only 15 min colocalizes with the intracellular parasites [18]. In agreement with this binding to the intraerythrocytic late stage pathogen, heparin has been described to inhibit the egress of merozoites from the parasitized RBC following its binding to MSP1 and to proteins found in the inner part of the RBC membrane [19]. Commercial heparin with a nominal mean molecular weight of 13,000 Da inhibits the in vitro growth of P. falciparum with an IC50 around $10 \mu \mathrm{g} / \mathrm{mL}$ (roughly $1 \mu \mathrm{M}$ ). Because heparin is eventually found in the blood, Plasmodium must have been exposed to it during its long coevolutionary history with humans and yet parasite resistance has not been described so far [15]. Several heparin modifications with reduced anticoagulant activity but maintaining significant antimalarial activity in vitro have been identified to have potential for novel drug development [20]. Of importance for an optimal inhibitory activity are the presence of $N$ - and $O$-sulfate residues and of $\geq 2$ sulfate units per disaccharide, specific spatial arrangements of sulfation requiring sulfate groups positioned together on a single saccharide unit, and a minimum chain length of six monosaccharide residues [15]. Overall, longer-chain heparin molecules of molecular weight $>3$ to $25 \mathrm{kDa}$ showed a trend toward having higher inhibitory activity than shorter-chain forms $<3 \mathrm{kDa}$ [20]. Periodate oxidation of non-sulfated uronic acid residues, which has been reported to abolish anticoagulation [21], increased the activity of some compounds [20]. 
Here we have explored different combinations of heparin modifications such as chain length, sulfation degree and position, and glycol-split, with the objective of identifying heparin-derived structures having a reduced anticoagulant activity, but maintaining a significant antimalarial potency.

\section{Materials and Methods}

Except where otherwise indicated, reagents were purchased from Sigma-Aldrich Corporation (St. Louis, MO, USA), and reactions were performed at room temperature (22 to $24{ }^{\circ} \mathrm{C}$ ). The lipids (all $\geq 99 \%$ purity according to thin layer chromatography analysis) 1,2-dioleoyl-sn-glycero -3-phosphocholine (DOPC), 1,2-dioleoyl-sn-glycero-3-phosphoethanolamine (DOPE), 1,2-dioleoyl-3 -trimethylammonium-propane (DOTAP), 1,2-distearoyl-sn-glycero-3-phosphoethanolamine- $N$ -[methoxy(polyethylene glycol)-2000] (DSPE-PEG), 1,2-dioleoyl-sn-glycero-3-phosphoethanolamine- $N$ -(lissamine rhodamine B sulfonyl) (DOPE-Rho), and cholesterol were purchased from Avanti Polar Lipids Inc. (Alabaster, AL, USA) and stored at $-20{ }^{\circ} \mathrm{C}$.

\subsection{Heparin Modification and Characterization}

Heparin and dermatan sulfate were obtained from animal mucosae and chondroitin sulfate from animal cartilage following standard industrial manufacturing procedures. Unfractionated heparin $(\mathrm{UH}$, $>12 \mathrm{kDa}$ ) was modified by depolymerization, desulfation, oversulfation, conjugation to primaquine (PQ), and glycol-split, and for the molecules with more than one modification, those were applied in this order. All modifications were performed as described elsewhere [22], and are succinctly described below.

For the depolymerization by nitrous acid [23,24], $4 \mathrm{~g}$ of heparin were dissolved in $65 \mathrm{~mL}$ of $\mathrm{H}_{2} \mathrm{O}$ and cooled to $4{ }^{\circ} \mathrm{C}$. After adding $75 \mathrm{mg}$ of $\mathrm{NaNO}_{2}$, the $\mathrm{pH}$ was adjusted to 2 with $0.1 \mathrm{M} \mathrm{HCl}$. The solution was stirred at $4{ }^{\circ} \mathrm{C}$ for $20 \mathrm{~min}$, and then the $\mathrm{pH}$ was brought to 7.0 by addition of $0.1 \mathrm{M} \mathrm{NaOH} .1 \mathrm{~g}$ of $\mathrm{NaBH}_{4}$ was added in several portions under stirring. After $2-3 \mathrm{~h}$, the $\mathrm{pH}$ was adjusted to 4 with $0.1 \mathrm{M} \mathrm{HCl}$, and 15 min later the solution was neutralized with $0.1 \mathrm{M} \mathrm{NaOH}$. The products, medium molecular weight heparin (MMWH, 8 to $12 \mathrm{kDa}$ ), low molecular weight heparin (LMWH, 4-8 kDa), and ultralow molecular weight heparin (ULMWH, $\leq 4 \mathrm{Kda}$ ) were precipitated with three volumes of ethanol, then dissolved in water and recovered by freeze-drying.

For 2-O-desulfation [22], $500 \mathrm{mg}$ of heparin were dissolved in $10 \mathrm{~mL}$ of $1 \mathrm{M} \mathrm{NaOH}$ and then heated at $85^{\circ} \mathrm{C}$ for $1 \mathrm{~h}$. After cooling below $30^{\circ} \mathrm{C}$, the solution was brought to pH 7 with $0.1 \mathrm{M} \mathrm{HCl}$ and heated at $70^{\circ} \mathrm{C}$ for $48 \mathrm{~h}$. Then, the samples were cooled, dialyzed against $\mathrm{H}_{2} \mathrm{O}$ (cellulose acetate membranes, 1000-Da cut-off), and recovered by freeze-drying.

For 6-O-desulfation [25], $200 \mathrm{mg}$ of sodium heparin salt was passed through a column of Amberlite IR-120, neutralized with pyridine, and lyophilized to obtain pyridinium heparin salt, which was solubilized in $20 \mathrm{~mL}$ of dry pryridine, to which $4 \mathrm{~mL}$ of $\mathrm{N}, \mathrm{O}$-bis(trimethylsilyl)acetamide were added. The mixture was incubated $2 \mathrm{~h}$ at $60^{\circ} \mathrm{C}$ until a clear solution was obtained. The reaction was terminated by adding $20 \mathrm{~mL}$ of water and the sample was dialyzed against $\mathrm{H}_{2} \mathrm{O}$, its $\mathrm{pH}$ adjusted above 7 with $\mathrm{NaOH}$, and dialyzed again immediately. The product was recovered by freeze-drying.

For $N$-desulfation and $N$-acetylation [22], pyridinium heparin salt, as previously obtained [25], was stirred at $20-25{ }^{\circ} \mathrm{C}$ in $\mathrm{Me}_{2} \mathrm{SO}$ :water (9:1) for $120 \mathrm{~min}$ to obtain molecules with $\mathrm{N}$-desulfation. For obtaining $N$-acetylation, the previous compounds were incubated with acetic anhydride in alkaline aqueous medium $\left(\mathrm{NaHCO}_{3}, 4{ }^{\circ} \mathrm{C}, 2 \mathrm{~h}\right)$. At the point of $\mathrm{N}$-desulfation or $\mathrm{N}$-acetylation, products were dialyzed against $\mathrm{H}_{2} \mathrm{O}$ and recovered by freeze-drying.

For oversulfation, to obtain a highly sulfated heparin, the procedure described by Maruyama et al. [26] was applied. Briefly, $100 \mathrm{mg}$ of sodium heparin salt were subjected to cation-exchange chromatography to obtain tributylamine salt, lyophilized, and dissolved in $0.8 \mathrm{~mL}$ of $\mathrm{N}, \mathrm{N}$-dimethylformamide, which contained an excess of pyridine-sulfur trioxide. After $1 \mathrm{~h}$ at $40{ }^{\circ} \mathrm{C}$, $1.6 \mathrm{~mL}$ of water were added, and the product was precipitated with three volumes of cold ethanol saturated with anhydrous sodium acetate and collected by centrifugation. The product was dissolved 
in water, dialyzed and recovered by freeze-drying. The resulting $\mathrm{SO}_{3}{ }^{-} / \mathrm{COO}^{-}$(i.e., $\mathrm{SO}_{3}{ }^{-} /$disaccharide) ratio (see below for its determination) of oversulfated heparin was 3.0 (as compared to 1.9-2.0 for native $\mathrm{UH}$ ).

Glycol-split was done by exhaustive periodate oxidation and borohydride reduction of $\mathrm{UH}$ or of a previously depolymerized and/or 2-O-desulfated sample [27]. In the first protocol, 250-mg samples were dissolved in $6 \mathrm{~mL}$ of $\mathrm{H}_{2} \mathrm{O}$, and $6 \mathrm{~mL}$ of $0.1 \mathrm{M} \mathrm{NaIO}_{4}$ were added. After stirring the solution at $4{ }^{\circ} \mathrm{C}$ for $16 \mathrm{~h}$ in the dark, $1 \mathrm{~mL}$ of ethylene glycol was added to stop the reaction, and the solutions were dialyzed against $\mathrm{H}_{2} \mathrm{O}$ for $16 \mathrm{~h}$. Solid sodium borohydride $(60 \mathrm{mg})$ was added to the retentate solutions in several portions under stirring. After $2-3 \mathrm{~h}$, the $\mathrm{pH}$ was adjusted to 4 with $0.1 \mathrm{M} \mathrm{HCl}$, and after stirring for $15 \mathrm{~min}$, the solutions were neutralized with $0.1 \mathrm{M} \mathrm{NaOH}$. After desalting and a second dialysis against $\mathrm{H}_{2} \mathrm{O}$, the final products were recovered by freeze-drying. In the second protocol, 250-mg samples were dissolved in $5 \mathrm{~mL}$ of $1 \mathrm{M} \mathrm{NaOH}$ and then heated at $60^{\circ} \mathrm{C}$ for $30 \mathrm{~min}$. After cooling below $30^{\circ} \mathrm{C}$, the solutions were brought to $\mathrm{pH} 7$ with $0.1 \mathrm{M} \mathrm{HCl}$ and heated at $70{ }^{\circ} \mathrm{C}$ for $48 \mathrm{~h}$ to induce the partial conversion of iduronic acid (IdoA) ${ }_{2} \mathrm{SO}_{3}$ to galacturonic acid. After cooling and dialyzing against $\mathrm{H}_{2} \mathrm{O}$, the product was recovered by freeze-drying.

PQ conjugation to MMWH: $2.0 \mathrm{~g}$ of MMWH were dissolved in $50 \mathrm{~mL}$ of deionized water and the $\mathrm{pH}$ of the solution was adjusted to 7.0. $1.35 \mathrm{~g}$ of PQ phosphate and $0.075 \mathrm{~g}$ of sodium cyanoborohydride were added and the reaction was stirred for $15 \mathrm{~min}$ at room temperature. $\mathrm{pH}$ was adjusted to 7.0 and stirring was continued for $24 \mathrm{~h}$. Then, an additional $0.075 \mathrm{~g}$ of sodium cyanoborohydride were added and the reaction continued for another $24 \mathrm{~h}$. The crude product was centrifuged at $5000 \mathrm{rpm}$ for $15 \mathrm{~min}$, and the supernatant was dialyzed against water until the permeate was colorless. $50 \mathrm{~g}$ of VOPC1074 resin were added to the retentate and the solution was stirred for $15 \mathrm{~min}$. Supernatant was discarded and the resin was washed with $400 \mathrm{~mL}$ of deionized water for $1.5 \mathrm{~h}$. The resin was filtered and treated with $250 \mathrm{~mL}$ of $15 \%(w / v) \mathrm{NaCl}$. The mixture was further stirred for $12 \mathrm{~h}$ at room temperature and then vacuum filtered. The filtrate was dialyzed again as before until chloride anions were not detected in the permeate. The product was recovered by freeze-drying.

The molecular weight of most samples was determined by high-performance size exclusion chromatography combined with triple detector array (HP-SEC/TDA) [28]; samples were dissolved at $20 \mathrm{mg} / \mathrm{mL}$ in $0.1 \mathrm{M} \mathrm{NaNO}_{3}$, and $100 \mu \mathrm{L}$ were injected in the SEC/TDA equipment (Viscotek GPCmax with Viscotek module 305 TDA (Malvern Instruments Ltd., Malvern, UK). $\mathrm{SO}_{3}{ }^{-} / \mathrm{COO}^{-}$ratio [29], anti-Xa factor [30], and activated partial thromboplastin time (aPTT) activity on dry basis [18] were determined according to established protocols.

\subsection{NMR Experimental Procedure}

NMR analysis was performed on a Bruker AVANCE 500 spectrometer operating at a frequency of $500.13 \mathrm{MHz}$ for ${ }^{1} \mathrm{H}$ and $125.75 \mathrm{MHz}$ for ${ }^{13} \mathrm{C}$ equipped with a $5 \mathrm{~mm}$ TBO probe. Spectra were processed with Bruker Topspin software version 3.6.2. Around $30-40 \mathrm{mg}$ of heparin samples were dissolved in $0.4 \mathrm{~mL}$ of $\mathrm{D}_{2} \mathrm{O}$ and the samples were held at a temperature of $298 \mathrm{~K}$ during data acquisition. Samples were analyzed by 1D and 2D NMR spectroscopy. Heteronuclear single-quantum coherence (HSQC), proton-proton correlation spectroscopy $\left({ }^{1} \mathrm{H}-{ }^{1} \mathrm{H}\right.$ COSY) and total correlation spectroscopy $\left({ }^{1} \mathrm{H}-{ }^{1} \mathrm{H}\right.$ TOCSY $)$ were used to characterize their structures. Chemical shift values were measured downfield from trimethylsilylpropionate sodium salt (TSP) as standard. The ${ }^{1} \mathrm{H}_{-}{ }^{1} \mathrm{H}$ TOCSY spectra were run using 32 scans per $\mathrm{t} 1$ increment (400 points) and a mixing time of $80 \mathrm{~ms} .{ }^{1} \mathrm{H}^{13} \mathrm{C}$ HSQC spectra were recorded with carbon decoupling during acquisition with 512 increments of 32 scans for each experiment. Two-dimensional diffusion ordered spectroscopy (DOSY) experiments were performed using stimulated echo sequence with bipolar gradient pulses [31]. Diffusion time $(\Delta)$ was set within the interval 220-320 ms. The pulsed gradients were incremented from $2 \%$ to $95 \%$ of the maximum strength in 16 spaced steps with a duration $(\delta)$ of $4-8 \mathrm{~ms}$. (For the internal reference TPS these values were $\Delta=$ $140 \mathrm{~ms}$ and $\delta=2.8 \mathrm{~ms}$ ). The $2 \mathrm{D}$ plots show diffusion coefficient values $\mathrm{D}$ in $\left[\mathrm{m}^{2} / \mathrm{s}\right]$. The NMR spectra of the heparin formulations selected for in vivo assays are presented in the Supplementary Materials. 


\subsection{P. falciparum Culture and Growth Inhibition Assays}

P. falciparum 3D7 parasites (Malaria Research and Reference Reagent Resource Center, MR4) were cultured at 4\% parasitemia and 3\% hematocrit in a hypoxia incubator (cell culture $\mathrm{CO}_{2}$ incubator, ESCO, Singapore) with a $92.5 \% \mathrm{~N}_{2}, 5.5 \% \mathrm{CO}_{2}$, and $2 \% \mathrm{O}_{2}$ gas mixture, using complete Roswell Park Memorial Institute (RPMI) 1640 medium (supplemented with $2 \mathrm{mM}$ L-glutamine, $50 \mu \mathrm{M}$ hypoxanthine, $5 \mathrm{~g} / \mathrm{L}$ Albumax II, $25 \mathrm{mM}$ HEPES, pH 7.2). A modification of this culture medium substituting Albumax II by $10 \%$ human inactivated plasma was also used when indicated. Serial dilutions in complete RPMI of each compound tested were incubated with P. falciparum 3D7 cells at 1\% pRBC and 3\% hematocrit in a final volume of $200 \mu \mathrm{L}$ in 96-well plates (SPL Life Sciences Co., Ltd., Gyeonggi-do, Korea). Every dilution was prepared in triplicate, and the parasites were incubated under hypoxia for $44 \mathrm{~h}$, when parasitemia was determined by flow cytometry, using either FACSCalibur or LSRFortesa (4 laser) cytometers (both from BD Biosciences, San Jose, CA, USA). For each cytometer, cell culture from each sample was diluted at either $0.024 \%$ or $0.03 \%$ hematocrit in phosphate buffered saline, $\mathrm{pH} 7.4$ (PBS), containing $0.5 \mathrm{nM}$ or $0.25 \mathrm{nM}$ SYTO 11, respectively. Parasitemia percentage was recorded with BD FACSDiva (BD Biosciences) software and further analyzed with GraphPad Prism 6 software (GraphPad Software, San Diego, CA, USA). The experiments with the samples of interest for in vivo assays were repeated three times, twice with the parasites synchronized at ring stage through a $5 \%(w / v)$ sorbitol treatment [32], and once with the parasites synchronized at trophozoite stage through a $70 \%$ Percoll treatment [33]. The rest of samples were tested in ring stage synchronized cultures.

\subsection{In Vitro Cytotoxicity Assays}

Human umbilical vein endothelial cells (HUVECs American Type Culture Collection, Manassas, VA, USA) were cultured in a $\mathrm{CO}_{2}$ incubator using Medium 199 (M199, LabClinics, Barcelona, Spain) supplemented with penicillin-streptomycin (100 units and $0.1 \mathrm{mg} / \mathrm{mL}$, respectively) and $10 \%$ fetal bovine serum (complete M199) in T-25 flasks (SPL Life Sciences Co., Ltd.), allowed to grow up to 70-80\% convergence and replated by trypsin treatment. Unspecific toxicity of the samples was tested with the WST-1 cell viability assay (Roche Applied Science, Penzberg, Germany), following the manufacturer's recommendations. Briefly, HUVECs were seeded in 96-well plates at a density of 5000 cells per well in $100 \mu \mathrm{L}$ of complete M199. After a 24 -h incubation at $37^{\circ} \mathrm{C}$, the medium was removed, and $90 \mu \mathrm{L}$ of fresh M199 were added together with $10 \mu \mathrm{L}$ of the sample of interest in PBS. HUVECs were placed back in the incubator for $24 \mathrm{~h}$ or $48 \mathrm{~h}$. At the moment of reading, $10 \mu \mathrm{L}$ of WST-1 reagent was added to each well, and, after an incubation of 3-4 h, absorbance at $440 \mathrm{~nm}$ was measured with an Epoch ${ }^{\mathrm{TM}}$ microplate spectrophotometer (BioTek Instruments Inc., Winooski, VT, USA). For each sample, three different concentrations were tested in triplicates, and each plate contained three seeded wells with $1 \%$ bleach (0\% viability control) and three wells with $10 \mu \mathrm{L}$ PBS (100\% viability control) as controls.

\subsection{Hemolysis Assays}

In a 96-well plate, $2 \mu \mathrm{L}$ of sample were added to $200 \mu \mathrm{L}$ of a $3 \%$ hematocrit $\mathrm{RBC}$ suspension in RPMI complete medium. After incubating for $3 \mathrm{~h}$ at $37^{\circ} \mathrm{C}$, samples were centrifuged at $1000 \times g$ for $5 \mathrm{~min}$ and $150 \mu \mathrm{L}$ of supernatant from each sample was transferred to a new plate where absorbance was measured at $541 \mathrm{~nm}$ in an Epoch ${ }^{\mathrm{TM}}$ microplate spectrophotometer (BioTek Instruments Inc.). Assays were done in triplicates, including positive (Triton X-100) and negative (PBS) controls. Data analysis was done with Excel and GraphPad Prism 6 software.

\subsection{In Vivo Toxicity Assays}

Seven-week-old BALB/c female mice (18-20 g, Janvier Laboratories, Le Genest-Saint-Isle, France) were maintained with ad libitum access to food and water under standard environmental conditions (20-24 ${ }^{\circ} \mathrm{C}$ and $12 \mathrm{~h} / 12 \mathrm{~h}$ light/dark cycle). The animals were anesthetized with isoflurane (4\% for induction and $2.5 \%$ for maintenance) in an oxygen stream to ensure administration and minimize 
injection stress, while delivery of a $200 \mu \mathrm{L}$ bolus was done intravenously. An adaptation of OECD 425 Test Guideline, which consisted of a single ordered dose progression, was followed in order to reduce the number of animals used. The first mouse received a dose one order of magnitude lower than the concentration proven safe in vitro, and the dose for the next animal was either decreased or increased by a factor of 3.2 depending on the observation or not, respectively, of acute effects on the first animal. After administration, each mouse was monitored for at least $48 \mathrm{~h}$ before the next animal was treated. In addition, other toxicity signs were evaluated maintaining all animals under observation for 14 days after dose injection. Following this protocol, different GAG concentrations (31.5, 100, 320, and $750 \mathrm{mg} / \mathrm{kg}$ ) were tested, prepared in PBS from a $50 \mathrm{mg} / \mathrm{mL}$ stock solution of the compound in sterile PBS. When any toxic effects were observed, including, among others, $>20 \%$ reduction in weight, aggressive and unexpected behavior or the presence of blood in faeces, animals were immediately anesthetized using a $100 \mathrm{mg} / \mathrm{kg}$ Ketolar plus $5 \mathrm{mg} / \mathrm{kg}$ Midazolan mixture and sacrificed by cervical dislocation. The highest dosage exhibiting absence of toxicity signs was considered the compound maximum tolerated dose. The animal care and use protocols followed adhered to the specific national and international guidelines specified in the Spanish Royal Decree 53/2013, which is based on the European regulation 2010/63/UE. The corresponding protocols were reviewed and approved by the Ethical Committee on Clinical Research from the Hospital Clínic de Barcelona (Reg. HCB/2018/1223, 23 January 2019).

\subsection{Antimalarial Activity in Mice}

A four-day suppressive test in BALB/c female mice was performed following pre-established protocols [34]. Briefly, animals were infected with $2 \times 10^{7}$ pRBCs from a Plasmodium yoelii yoelii 17XL-infected mouse (20-30\% parasitemia). Between $3 \mathrm{~h}$ and $4 \mathrm{~h}$ later, mice were treated intravenously with $100 \mu \mathrm{L}$ of the test samples; an infection control group treated with PBS only and a treatment control group dosed with $5 \mathrm{mg} / \mathrm{kg}$ chloroquine were also included. For the next three days animals were treated following the same procedure at the same times. From day 2 post-infection, blood samples were collected by tail punction, and $\mathrm{pRBC}$ percentage was determined by either flow cytometry or blood smear preparation stained with Giemsa followed by optical microscope analysis.

\subsection{Preparation of Heparin-Coated Liposomes}

The lipid formulation DOPC:DOPE:cholesterol:DOTAP:DSPE-PEG:DOPE-Rho 46.5:30:20:2:2:0.5 was obtained by mixing stock solutions of lipids in chloroform in a round bottom flask. The solvent was evaporated by $\mathrm{N}_{2}$ flow and the lipid film was further dried under vacuum for $1 \mathrm{~h}$. Then, lipids were hydrated in $1 \mathrm{~mL}$ of PBS and vortexed for $3 \mathrm{~min}$, to achieve a final total lipid concentration of $20 \mathrm{mM}$. To obtain unilamelar liposomes of regular size, the suspension was extruded through $200 \mathrm{~nm}$ polycarbonate membranes (Avanti Polar Lipids, Inc.) using a mini extruder device (Avanti Polar Lipids, Inc.). UH at $20 \mathrm{mg} / \mathrm{mL}$ was activated for $30 \mathrm{~min}$ in $25 \mathrm{mM}$ 2-(N-morpholino)ethanesulfonic acid, pH 5, with $39 \mathrm{mM}$ 1-ethyl-3-(3-dimethylaminopropyl)carbodiimide (BioRad) and $55 \mathrm{mM}$ $N$-hydroxysulfosuccinimide. Then, $500 \mu \mathrm{L}$ of activated UH were added to a liposome suspension containing $0.67 \mathrm{mM}$ total lipid in $3 \mathrm{~mL}$ of PBS and incubated under stirring for $2 \mathrm{~h}$. To remove unbound heparin, the sample was centrifuged in a $100 \mathrm{kDa}$ cut-off Amicon ${ }^{\circledR}$ Ultra centrifugal filter and PBS was added to recover the initial volume; this process was repeated five times, until heparin was not detected in the recovered washes according to Alcian Blue quantification [35]. Heparin concentration in the final UH-coated liposome sample was $1.7 \mathrm{mg} / \mathrm{mL}$, corresponding to a ca. 1:15 UH:total lipid molar ratio. Liposomes were detected in plasma by rhodamine fluorescence detection in an Infinite ${ }^{\circledR}$ M Nano microplate reader spectrofluorometer (Tecan, Männedorf, Switzerland) at 553 nm excitation and $586 \mathrm{~nm}$ emission. 


\subsection{Plasma Half-Life Determination}

$\mathrm{BALB} / \mathrm{c}$ mice were inoculated intravenously with $18 \mathrm{mg} / \mathrm{kg}$ of the compounds to be tested (UH, 2-O-desulfated glycol-split MMWH, or UH-coated liposomes). Blood was collected at different times after administration via facial vein or cava vein extraction under isoflurane anesthesia. Collected blood was mixed with $1 / 10$ volume of $3.2 \%$ sodium citrate, and plasma was separated by centrifugation $(500 \times g)$ and frozen until quantification with the Heparin Red ${ }^{\circledR}$ method (Redprobes UG, Münster, Germany), following published protocols [36]. In brief, $20 \mu \mathrm{L}$ of non-treated mouse plasma containing different heparin concentrations $(30,20,15,10,7.5,5,2,1$, and $0 \mu \mathrm{g} / \mathrm{mL})$ and of the collected plasma from treated mice were placed in duplicates per mouse and time point in a 96-well plate. Enhancer solution, $1 \mathrm{M} \mathrm{MgCl}_{2}$ and Heparin $\operatorname{Red}^{\circledR}$ were mixed (85.5:4.5:1 for UH samples and 171:9:1 for 2-O-desulfated glycol-split MMWH), $80 \mu \mathrm{L}$ of the mixture was added to each well, the plate was shaken for $3 \mathrm{~min}$, and fluorescence was recorded at $590 \mathrm{~nm}$ excitation and $645 \mathrm{~nm}$ emission, using a Synergy microplate reader (BioTek Instruments Inc.).

\subsection{Ethics Statement}

The human blood and plasma used for P. falciparum in vitro cultures were commercially obtained from the Banc de Sang $i$ Teixits (www.bancsang.net). Purchased units had been discarded for transfusion, mostly due to an excess of blood relative to anticoagulant solution. Prior to use, blood and plasma units underwent the analytical checks specified in the current legislation. Before being delivered, to guarantee the non-identification of the blood donor, unit data were anonymized and irreversibly dissociated, and any identification tag or label was removed. No blood data were or will be supplied, and the studies reported here were performed in accordance with the current Spanish Ley Orgánica de Protección de Datos and Ley de Investigación Biomédica and under protocols reviewed and approved by the Ethical Committee on Clinical Research from the Hospital Clinic de Barcelona (Reg. HCB/2018/1223, 23 January 2019).

\section{Results}

\subsection{Antimalarial Activity Determination of Different Natural GAGs}

Preliminary in vitro antimalarial activity assays of different GAG types (Figure 1a-c) were consistent with previously published data [20] indicating that a $>30$-fold higher amount of dermatan or chondroitin sulfate than that of heparin was required to obtain similar parasite growth inhibitions (Figure 1d-f). A higher sulfate content in heparin (1.9-2.0 sulfate groups/disaccharide) correlated with its higher antimalarial activity. The source from which heparin was obtained did not have a significant influence on its capacity to inhibit P. falciparum growth in vitro.

\subsection{Effect on Antimalarial Activity of Heparin Molecular Weight}

Because higher molecular weights of heparin are usually related with undesired secondary effects, such as induced thrombocytopenia or hemorrhage [37], in vitro parasite growth inhibition was determined for unfractionated heparin from pig lung and for different fractions obtained from this molecule as precursor. In agreement with previous reports [15], both the curves of percentage of growth inhibition and the derived IC50 values showed that shorter heparin chain lengths had a reduced antimalarial activity, especially for ULMWH (Figure 2). Decreasing the number of disaccharide units below nine significantly lowered the antiplasmodial activity of heparin in vitro. 


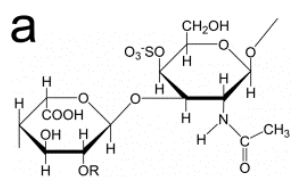

d$$
\text { I }
$$

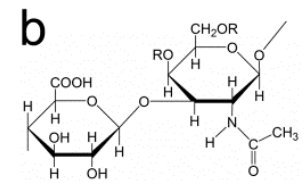

e
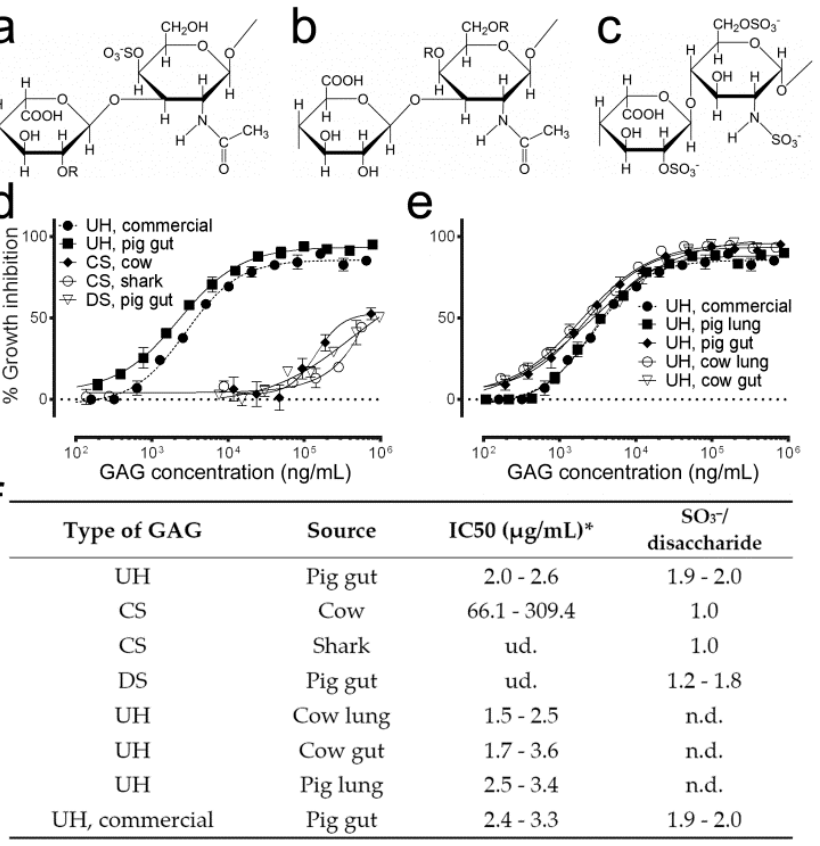

Figure 1. In vitro antimalarial activity of glycosaminoglycans (GAGs) from different origin. $(\mathbf{a}-\mathbf{c})$ Structures of the most represented disaccharide units in (a) dermatan sulfate, (b) chondroitin sulfate and (c) heparin. $\mathrm{R}: \mathrm{H}_{\text {or }} \mathrm{SO}_{3}{ }^{-}$. (d,e) Graphs comparing the in vitro Plasmodium falciparum growth inhibition activity of different GAGs. (f) Description of the GAGs tested in panels (d,e). UH: unfractionated heparin, CS: chondroitin sulfate, DS: dermatan sulfate. ud.: undetected, n.d.: not determined. Commercial UH was purchased from Sigma Aldrich (Cat. No. H-4784). * IC50 has been calculated by non-linear regression of the percentage of growth inhibition against molecule concentration. IC50 range represents 95\% confidence interval of one experiment.

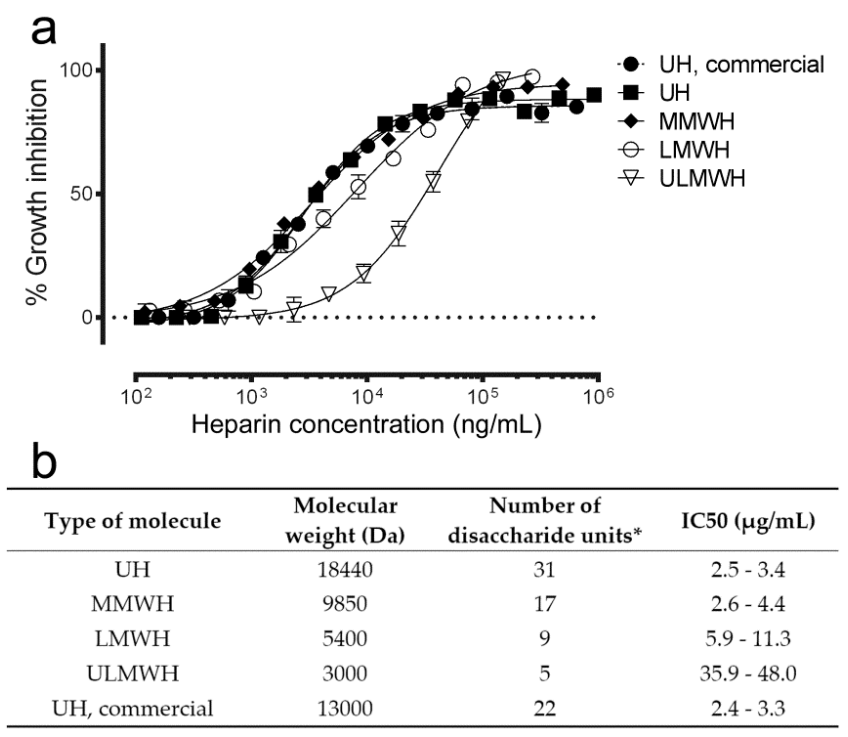

Figure 2. In vitro antimalarial activity of heparins with different molecular weight. (a) In vitro $P$. falciparum growth inhibition activity assay of heparin fractions of decreasing chain lengths. (b) Description of the heparin samples tested in panel (a). MMWH: medium molecular weight heparin, LMWH: low molecular weight heparin, ULMWH: ultralow molecular weight heparin. * The approximate number of disaccharide units was calculated considering the molecular weight of the trisulfated disaccharide unit as $590.9 \mathrm{~g} / \mathrm{mol}$. IC50 range represents $95 \%$ confidence interval of one experiment. 


\subsection{Effect of Sulfate Group Removal on the Antimalarial Activity of Heparin}

Because there is a direct correlation between the number and position of sulfate groups and the anticoagulant activity of heparin [38], the antimalarial capacity of different desulfated heparin structures was analyzed (Figure 3). 2-O desulfation of IdoA together with glucosamine $N$-desulfation completely suppressed antimalarial activity, whereas 6-O-desulfation and $\mathrm{N}$-desulfation significantly increased the IC50 of the resulting structures to $>300 \mu \mathrm{g} / \mathrm{mL}$ (Table 1).

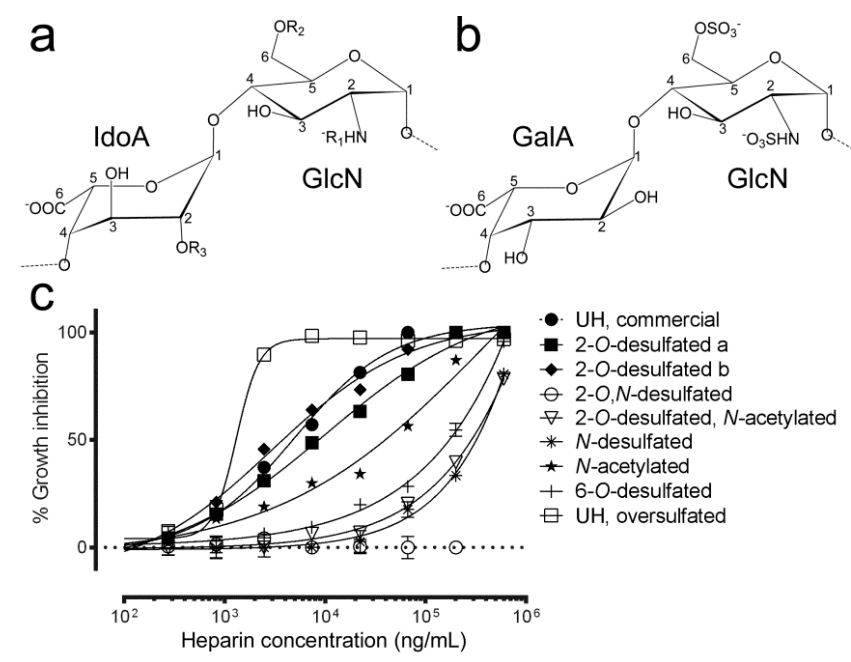

Figure 3. In vitro antimalarial activity of heparins with different sulfation patterns. (a,b) Structures obtained after desulfation (see Table 1 for the definition of chemical groups $R_{1}, R_{2}$, and $R_{3}$ ). IdoA: iduronic acid, GlcN: glucosamine, GalA: galacturonic acid. (c) In vitro P. falciparum growth inhibition activity assay of heparin fractions with different sulfation patterns.

Table 1. Description of the heparin samples tested in Figure 3.

\begin{tabular}{|c|c|c|c|c|c|}
\hline Sample & Molecule of Origin & Structure & Molecular Weight (Da) & aPTT (IU/mg) & IC50 $(\mu \mathrm{g} / \mathrm{mL})$ \\
\hline 2-O-desulfated structure a & $\mathrm{UH}$ & $\mathrm{R}_{1}, \mathrm{R}_{2}: \mathrm{SO}_{3}^{-} ; \mathrm{R}_{3}: \mathrm{H}$ & 10,721 & 34 & $7.6-13.5$ \\
\hline 2-O-desulfated structure b & $\mathrm{UH}$ & $\mathrm{b}$ & 14,023 & 63 & $2.2-4.1$ \\
\hline 2-O-desulfated, $N$-desulfated & 2-O-desulfated a & $\mathrm{R}_{1}, \mathrm{R}_{3}: \mathrm{H} ; \mathrm{R}_{2}: \mathrm{SO}_{3}^{-}$ & 13,459 & 20 & ud. \\
\hline 2-O-desulfated, $\mathrm{N}$-acetylated & 2-O-desulfated a & $\mathrm{R}_{1}: \mathrm{Ac} ; \mathrm{R}_{2}: \mathrm{SO}_{3}^{-} ; \mathrm{R}_{3}: \mathrm{H}$ & 10,868 & 24 & $>1000$ \\
\hline $\mathrm{N}$-desulfated & $\mathrm{UH}$ & $\mathrm{R}_{2}, \mathrm{R}_{3}: \mathrm{SO}_{3}{ }^{-} ; \mathrm{R}_{1}: \mathrm{H}$ & 15,771 & 42 & $>1000$ \\
\hline$N$-acetylated & $\mathrm{N}$-desulfated & $\mathrm{R}_{2}, \mathrm{R}_{3}: \mathrm{SO}_{3}{ }^{-} ; \mathrm{R}_{1:} \mathrm{Ac}$ & 15,963 & 91 & $>300$ \\
\hline 6-O-desulfated & $\mathrm{UH}$ & $\mathrm{R}_{1}, \mathrm{R}_{3}: \mathrm{SO}_{3}{ }^{-} ; \mathrm{R}_{2}: \mathrm{H}$ & 14,521 & 45 & $>1000$ \\
\hline $\mathrm{UH}$ & - & $\mathrm{R}_{1}, \mathrm{R}_{2}, \mathrm{R}_{3}: \mathrm{SO}_{3}^{-}$ & 15,792 & 203 & $2.0-2.6$ \\
\hline UH, oversulfated & $\mathrm{UH}$ & $\mathrm{R}_{1}, \mathrm{R}_{2}, \mathrm{R}_{3}: \mathrm{SO}_{3}^{-}$ & 19,990 & 94 & $1.2-1.4$ \\
\hline UH, commercial & - & $\mathrm{R}_{1}, \mathrm{R}_{2}, \mathrm{R}_{3}: \mathrm{SO}_{3}^{-}$ & 13,000 & n.d. & $4.1-6.0$ \\
\hline
\end{tabular}

ud.: undetected, n.d.: not determined.

2-O-desulfation of IdoA significantly reduced the anticoagulant activity of heparin according to aPTT values. This modification had only a moderate effect on antimalarial activity, except when the glucosamine $N$-sulfate was also removed or substituted by an acetyl group, which completely abolished the antiplasmodial action of heparin. The affinity for antithrombin of the two 2-O-desulfated samples maintaining a good inhibition of Plasmodium growth is likely suppressed, since anti-Xa activity was very low (3 IU/mg and $9 \mathrm{IU} / \mathrm{mg}$ for 2-O-desulfated structures in Figure 3 panels a and b, respectively) when compared to that of UH (192 IU/mg). The galacturonic acid (stereoisomer of IdoA) modification, shown in panel $\mathrm{b}$ in Figure 3, had an in vitro antimalarial activity that improved that of commercial UH. This inversion increases the chain rigidity [38], and it has been suggested that an increment in such rigidity of heparin-like molecules can produce an increase of antimalarial activity [15]. 
Oversulfated heparin exhibited an increased antimalarial activity relative to unfractionated heparin, although this positive result was not accompanied by a dramatic decrease in anticoagulant activity (94 IU/mg vs. $203 \mathrm{IU} / \mathrm{mg}$, respectively).

\subsection{Effect of Glycol-Split on the Antimalarial and Anticoagulant Activities of Heparin}

Whereas a moderate degree of glycol-split (Figure 4a) slightly reduced the antimalarial activity of heparin (Figure 4b), it dramatically lowered its anticoagulation action according to the aPTT assay (72 IU/mg vs. $203 \mathrm{IU} / \mathrm{mg}$ relative to unfractionated heparin; Figure 4c). When glycol-split was applied to the 2-O-desulfated structure having the best balance between antimalarial and anticoagulant activities (Figure 3b), aPTT was further decreased (44 IU/mg), although this was accompanied by a decrease in the capacity to inhibit Plasmodium growth in vitro. This sample was derived from the 2-O-desulfated structure shown in Figure 3b, which had a higher degree of oxidation leading to increased glycol-split, and therefore to more open rings and flexibility than the sample derived from unfractionated heparin. Glycol-split treatment of heparin chains has been described to increase chain flexibility and to decrease interactions with coagulation factors [39], as evidenced by the dramatic decrease in antithrombin binding of glycol-split heparins (Figure 4c).
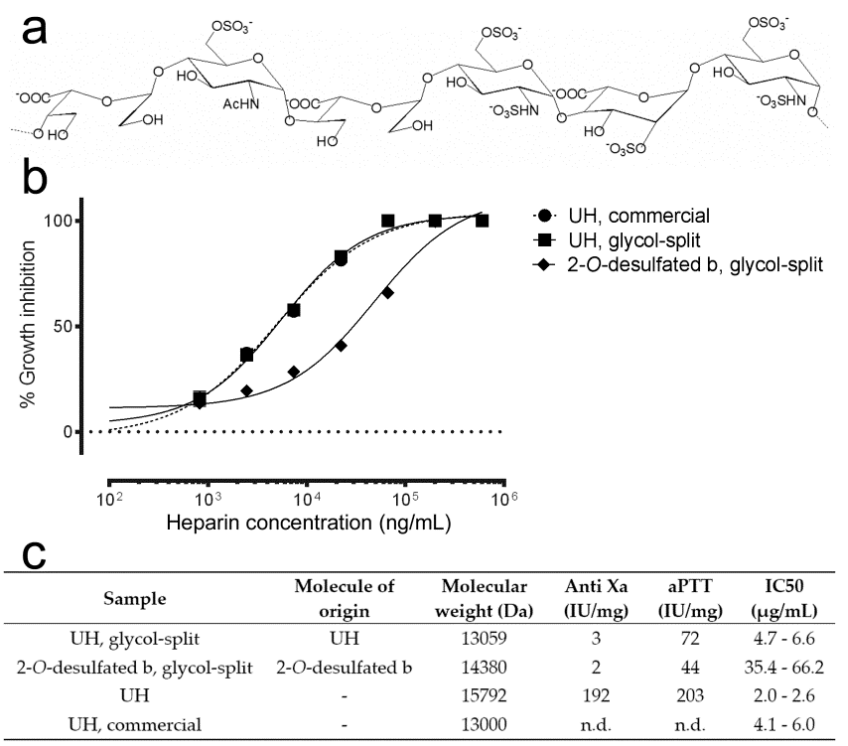

Figure 4. Effect of glycol-split on the in vitro antimalarial activity of heparin. (a) Structure of the heparin chain after glycol-split treatment. (b) In vitro P. falciparum growth inhibition activity assay of heparin fractions with and without glycol-split. (c) Description of the heparin samples tested in panel (b). n.d.: not determined.

\subsection{Selection of Heparin Forms Having Reduced Anticoagulant Activity but Maintaining Significant Plasmodium Growth Inhibition}

To advance toward the use of heparin as a clinically useful antimalarial drug, keeping a low anticoagulant activity will be as important as maintaining its capacity to inhibit the growth of the parasite, and therefore a delicate balance has to be met between these two indicators. Several structures having less anticoagulant activity than unfractionated heparin were obtained when applying different combinations of the parameters explored above, i.e., chain length, sulfation degree and position, and glycol-split (Table 2). None of the resulting preparations exhibited significant hemolysis or unspecific toxicity in HUVEC cultures. Since heparins with reduced anticoagulant activity could be used in vivo in larger amounts, a sufficient antimalarial activity could be in principle obtained with them, even if they have a relatively low antiplasmodial potency. 
Table 2. Characterization of heparin samples that combine different chemical modifications. Shadowed in gray are the formulations selected for in vivo assays.

\begin{tabular}{|c|c|c|c|c|c|c|c|}
\hline Sample & Mw (Da) & $\mathrm{SO}_{3}{ }^{-} /$Disaccharide & $\begin{array}{c}\text { IC50 } \\
(\mu \mathrm{g} / \mathrm{mL} \pm \mathrm{SD})\end{array}$ & $\begin{array}{c}\text { IC90 } \\
(\mu \mathrm{g} / \mathrm{mL} \pm \mathrm{SD})\end{array}$ & $\begin{array}{c}\text { aPTT } \\
\text { (IU/mg) }\end{array}$ & $\begin{array}{c}\text { In Vitro Toxicity }^{1} \\
(\% \pm \text { SD })\end{array}$ & $\begin{array}{c}\text { Hemolysis }^{1} \\
(\% \pm \text { SD) }\end{array}$ \\
\hline MMWH_2 & 11,000 & 1.9 & $33.7 \pm 21.8$ & $374.8 \pm 189.3$ & 130 & $0.0 \pm 6.0$ & $0.5 \pm 0.2$ \\
\hline $\begin{array}{c}\text { 2-O-desulfated } \\
\text { MMWH_1 }\end{array}$ & 8771 & 1.6 & $80.7 \pm 5.0$ & $270.3 \pm 42.5$ & 38 & $10.0 \pm 3.0$ & $0.3 \pm 0.4$ \\
\hline $\begin{array}{l}\text { 2-O-desulfated } \\
\text { MMWH_2 }\end{array}$ & 8776 & 1.5 & $91.9 \pm 9.0$ & $351.9 \pm 43.4$ & 23 & $0.0 \pm 2.3$ & $2.0 \pm 2.0$ \\
\hline $\begin{array}{c}\text { 2-O-desulfated } \\
\text { MMWH_3 }\end{array}$ & 10,198 & 1.5 & $59.1 \pm 16.5$ & $487.9 \pm 161.3$ & 53 & $17.9 \pm 2.1$ & $0.5 \pm 0.2$ \\
\hline $\begin{array}{l}\text { 2-O-desulfated } \\
\text { glycol-split } \\
\text { MMWH_1 }\end{array}$ & 7388 & 1.8 & $79.6 \pm 5.4$ & $893.1 \pm 321.0$ & 6 & $7.3 \pm 4.5$ & $0.4 \pm 0.1$ \\
\hline $\begin{array}{c}\text { 2-O-desulfated } \\
\text { glycol-split } \\
\text { MMWH_2 }\end{array}$ & 7037 & 1.5 & $84.2 \pm 13.4$ & $303.4 \pm 46.2$ & 5 & $3.6 \pm 5.4$ & $0.0 \pm 0.0$ \\
\hline $\begin{array}{c}\text { 2-O-desulfated } \\
\text { ULMWH_2 }\end{array}$ & 4450 & 1.4 & $129.2 \pm 13.1$ & $262.5 \pm 16.1$ & ud. & $37.0 \pm 9.9$ & $0.2 \pm 0.0$ \\
\hline $\begin{array}{c}\text { 2-O-desulfated } \\
\text { glycol-split } \\
\text { ULMWH_1 }\end{array}$ & 4024 & 1.7 & $104.4 \pm 6.0$ & $192.4 \pm 16.2$ & ud. & $2.5 \pm 2.3$ & $0.0 \pm 0.2$ \\
\hline $\begin{array}{c}\text { 2-O-desulfated } \\
\text { glycol-split } \\
\text { ULMWH_2 }\end{array}$ & 3800 & 1.6 & $130.3 \pm 15.5$ & $200.5 \pm 111.6$ & ud. & $11.5 \pm 8.0$ & $0.0 \pm 0.1$ \\
\hline UH, commercial & 13,000 & $1.9-2.0$ & $9.4 \pm 4.4$ & $135.5 \pm 12.8$ & 197 & $0.0 \pm 6.0$ & $0.0 \pm 0.0$ \\
\hline
\end{tabular}

${ }^{1}$ Reported in vitro toxicity in human umbilical vein endothelial cell (HUVEC) culture (\% of cell death) and hemolysis data (\% of lysed RBCs) have been calculated with $2 \mathrm{mg}$ heparin $/ \mathrm{mL}$. The numbers after two compounds with the same name indicate that those samples are replicates, made in order to check the reproducibility of the procedure and tested separately to corroborate if there were any differences in antimalarial or anticoagulant activity. n.d.: not determined, ud.: undetected.

\subsection{Conjugation of Heparin with $P Q$}

To explore alternative strategies that could compensate for the loss in antimalarial activity of modified heparins, the antimalarial drug PQ was conjugated to the reducing end of MMWH (Figure 5). The combination of both molecules resulted in an antimalarial potency that significantly improved that of MMWH alone (Table 3). This result could be interpreted as a targeting effect of heparin, whose known affinity for pRBCs $[17,18]$ might contribute to a more efficient delivery of PQ to target cells. This approach offers a potential solution to recover part of the antimalarial activity of heparin, which is lost with the chemical modifications that confer it a reduced anticoagulant action.

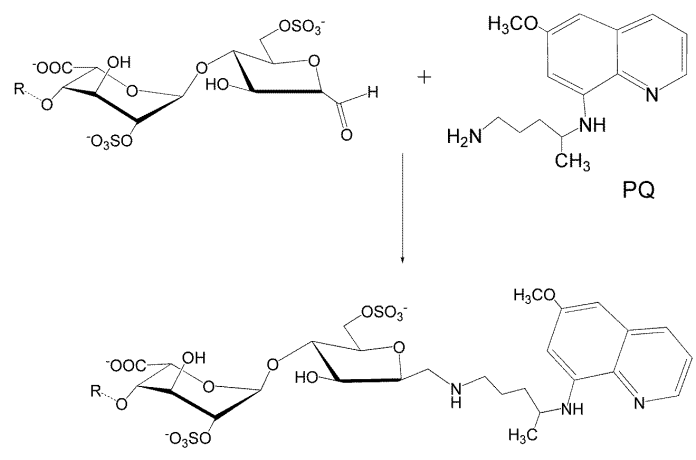

Figure 5. Reaction between the reducing end of heparin and primaquine (PQ), and the resulting molecular structure. 
Table 3. In vitro P. falciparum growth inhibition activity assay of the heparin-PQ conjugate.

\begin{tabular}{ccc}
\hline Sample & Mw (Da) & IC50 $(\mu \mathbf{M}) \pm$ SD \\
\hline MMWH-PQ & 13,945 & $1.16 \pm 0.40$ \\
MMWH_1 & 11,000 & $3.1 \pm 2.0^{1}$ \\
PQ & 259 & $5.20 \pm 1.33$ \\
\hline
\end{tabular}

${ }^{1}$ The molar concentration of MMWH was calculated considering a molecular weight of 11,000 kDa.

\subsection{Antimalarial Activity In Vivo of Heparin-derived Structures}

For antimalarial in vivo assays were selected those heparin-derived structures that exhibited a good balance of in vitro safety (neither cytotoxicity nor hemolysis observed), low anticoagulant activity ( $\leq 23 \mathrm{IU} / \mathrm{mL}$ in aPTT assays) and not too low antimalarial activity (IC50 at least around $100 \mu \mathrm{g} / \mathrm{mL}$ ). This led to the selection of the five heparins shadowed in grey in Table 2, whose in vivo toxicity was determined as an additional preliminary check. All five samples were not toxic when administered intravenously at $320 \mathrm{mg} / \mathrm{kg}$ (Table 4). Full characterization by NMR (Figures S1-S8) was performed to confirm presence of the expected modifications.

When the five selected heparin formulations were tested in vivo in the P. yoelii yoelii 17XL rodent malaria model by intravenous administration in a 4-day suppressive test, neither animal survival nor parasitemia load were significantly improved relative to the control PBS-treated group (Figure 6). Although a tendency was observed toward increased survival time of heparin-treated mice, this result could be due to small differences in parasite inoculation among different animals.

Table 4. Compilation of relevant data for heparin samples to be used in vivo.

\begin{tabular}{cccccc}
\hline Sample & $\begin{array}{c}\text { IC50 } \\
(\mu \mathrm{g} / \mathbf{m L} \pm \mathbf{S D})\end{array}$ & $\begin{array}{c}\text { aPTT } \\
(\mathbf{I U} / \mathbf{m g})\end{array}$ & $\begin{array}{c}\text { In Vitro Toxicity } \\
(\mathbf{\%} \pm \mathbf{S D})\end{array}$ & $\begin{array}{c}\text { Hemolysis }^{\mathbf{1}} \\
(\mathbf{\%} \pm \mathbf{S D})\end{array}$ & $\begin{array}{c}\text { In Vitro } \\
\text { Toxicity }^{2}\end{array}$ \\
\hline $\begin{array}{c}\text { 2-O-desulfated } \\
\text { MMWH_2 }\end{array}$ & $91.95 \pm 8.97$ & 23 & $0.00 \pm 2.34$ & $1.99 \pm 2.05$ & $>320 \mathrm{mg} / \mathrm{kg}$ \\
\hline ULMWH & $49.31 \pm 5.97$ & 6 & $6.83 \pm 9.18$ & $0.21 \pm 0.13$ & $>320 \mathrm{mg} / \mathrm{kg}$ \\
\hline $\begin{array}{c}\text { 2-O-desulfated } \\
\text { glycol-split } \\
\text { MMWH_1 }\end{array}$ & $79.60 \pm 5.38$ & 6 & $7.26 \pm 4.55$ & $0.36 \pm 0.09$ & $>750 \mathrm{mg} / \mathrm{kg}$ \\
\hline $\begin{array}{c}\text { 2-O-desulfated } \\
\text { glycol-split } \\
\text { MMWH_2 }\end{array}$ & $84.20 \pm 13.45$ & 5 & $3.61 \pm 5.42$ & $0.00 \pm 0.03$ & $>750 \mathrm{mg} / \mathrm{kg}$ \\
\hline $\begin{array}{c}\text { 2-O-desulfated } \\
\text { glycol-split } \\
\text { ULMWH_1 }\end{array}$ & $104.40 \pm 6.03$ & 0 & $2.49 \pm 2.35$ & $0.00 \pm 0.22$ & $>750 \mathrm{mg} / \mathrm{kg}$
\end{tabular}

${ }^{1}$ Reported in vitro toxicity in HUVEC culture (\% of cell death) and hemolysis data (\% of lysed red blood cells) have been calculated with $2 \mathrm{mg}$ heparin/mL. ${ }^{2}$ In vivo toxicity refers to the highest concentration tested that did not induce for 15 days after administration any acute or chronic effect in mice.

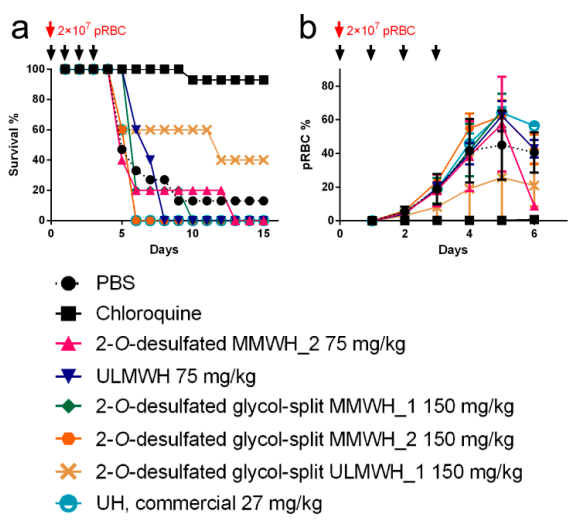

Figure 6. Antimalarial activity in vivo of heparin-derived structures. Mice survival curves (a) and parasitemia percentage (b) following treatment with the tested compounds at the concentrations indicated. The black arrows indicate the times of test sample administration. $n=5$ in each group, except PBS- $(n=15)$ and chloroquine-treated mice $(n=14)$. 


\subsection{Determination of the Circulation Time of Intravenously Administered Heparin}

The poor efficiency of the selected formulations for the treatment of in vivo infections could be due, among other reasons, to a rapid elimination from the blood circulation. Because the antimalarial activity of heparin resides in its inhibition of the red blood cell invasion by the merozoite form of the parasite, a phase that lasts only a few minutes within the P. falciparum 48-h intraerythrocytic life cycle, a rapid elimination from the blood circulation would significantly reduce the chances of being present when invasion takes place. Commercial UH and 2-O-desulfated glycol-split MMWH_2 had similar plasma half-lives (25.7 and $29.1 \mathrm{~min}$, respectively; Figure 7) and became undetectable about $3 \mathrm{~h}$ after intravenous administration to mice, suggesting a fast clearance possibly due to interactions with plasma components. In addition, the in vitro activity of these two heparins became reduced when tested in growth medium supplemented with $10 \%$ human plasma (Figure 8 ), indicating that such plasma interactions might compete with the binding to merozoites of heparin, thus decreasing its antimalarial activity.

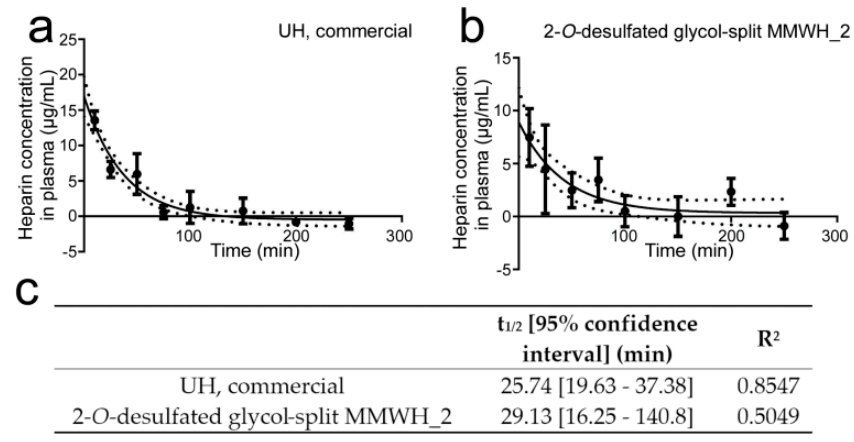

Figure 7. Determination of blood circulation time for unfractionated heparin (UH) and 2-O-desulfated glycol-split MMWH_2. (a,b) Concentration of both heparins in mouse plasma along time following intravenous administration to three male and three female mice for each time point. (c) Blood half-life values $\left(t_{1 / 2}\right)$ for both samples and $R^{2}$ of the plotted curves.

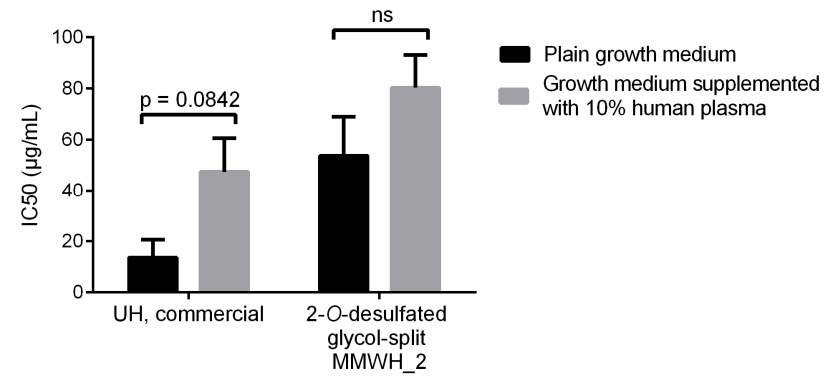

Figure 8. IC50 of the two samples from Figure 7 in P. falciparum in vitro cultures grown in either plain growth medium or in growth medium supplemented with $10 \%$ human plasma. ns: not significant.

To prevent the absorption of serum proteins, the surface of liposomes can be decorated by hydrophilic and bio-compatible polyethylene glycol (PEG) polymers, which can significantly extend blood circulation times [40]. We explored whether the covalent link of heparin to the surface of PEGylated liposomes increased its blood half-life and affected its antimalarial activity in vitro. The circulation half-life of UH-coated liposomes was $22.4 \mathrm{~min}$ (18.4-28.6 min with 95\% confidence; Figure 9a), but they could be detected up to $4 \mathrm{~h}$ after administration (data not shown). The initial UH concentration $10 \mathrm{~min}$ after administration was ca. $40 \mu \mathrm{g} / \mathrm{mL}$ for UH-coated liposomes (as compared to ca. $17 \mu \mathrm{g} / \mathrm{mL}$ for free UH; Figure 7a), whereas the antimalarial activity in vitro of UH-covered liposomes had roughly the same IC50 as UH alone (Figure 9b). Although the liposomal formulation did not significantly extend the half-life of heparin in circulation, it did increase the time that the 
molecule was found in plasma at a higher concentration than its in vitro IC50 (21 min for free UH and 49 min for UH-coated liposomes).

a

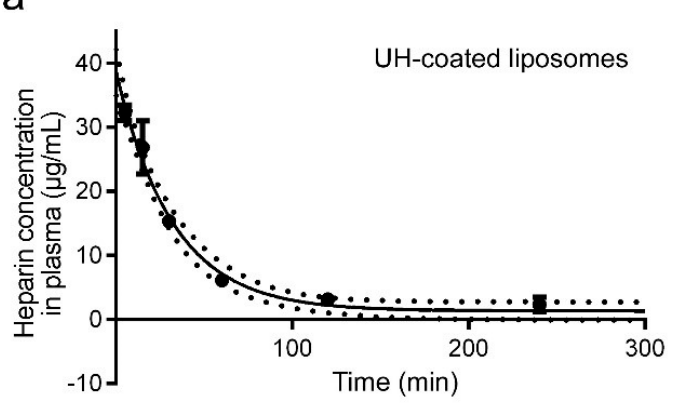

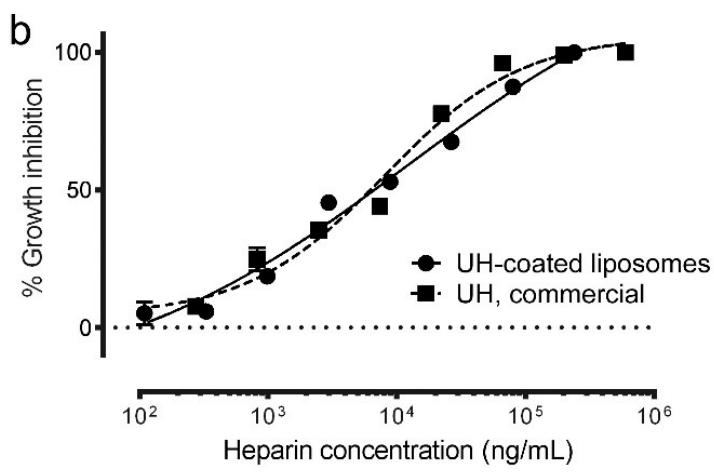

Figure 9. Characterization of circulation time and antimalarial activity of UH-coated liposomes. (a) Concentration of liposome-bound $\mathrm{UH}$ in mouse plasma along time following intravenous administration to 2 female mice for each time point. (b) P. falciparum growth inhibition activity assay of UH-coated liposomes and free UH.

\section{Discussion}

Previous works with sulfated GAGs, heparin modifications, and other sulfated compounds that could act as antimalarials $[15,20,41]$ had placed this type of molecules as good candidates for the development of new drugs. Our data indicate that chemical modification of heparin might not be the only path to a GAG that could offer good perspectives of entering the clinical pipeline. Chondroitin sulfate has in vitro antimalarial activity comparable to those of the chemically desulfated structures prepared in this work, to which has to be added the benefit of a low anticoagulant activity [41]. Other sources of sulfated polysaccharides exhibiting antimalarial activity and inhibition of RBC invasion by Plasmodium at low anticoagulant concentrations are certain marine organisms such as algae, sea cucumbers and sponges [41]. Dermatan sulfate has also been explored to control Plasmodium berghei infections in mice, but although it could reduce parasitemia in the treated groups, there was no significant effect on animal survival [14]. These and other natural polysaccharides could be modified to improve their antimalarial capacity in a similar way as it was done with sevuparin, a heparin derivative that has reached phase I/II of clinical trials for malaria treatment as adjuvant therapy [42].

Besides their potential applications as antimalarial therapy through their blocking activity of RBC invasion by Plasmodium merozoites, the heparin modifications explored here could be of use for other pathological features of the disease. In severe malaria, pRBCs can adhere to naïve RBCs to form cell clumps termed rosettes, which can reduce the blood circulation in capillaries leading to life-threatening conditions [13]. Because heparin and other GAGs can disrupt rosettes, their administration as adjuvant therapy could reduce their formation. As previous research in this field has proven, the molecular structure of the GAG chains that interact with rosette forming pRBCs is variable and highly dependent on the particular Plasmodium strain [13]. In this regard, the implementation of a chemical modification toolbox including reactions like those presented in this work will be highly instrumental in the adaptation of these polysaccharides to their target cell types.

Of the different heparin modifications assayed in this work, a combination of reduction in size (MMWH), 2-O-desulfation of IdoA, and glycol-split has offered the best balance toward a structure having low anticoagulant activity but maintaining a still acceptable in vitro antimalarial action in P. falciparum cultures while showing low hemolysis and in vitro and in vivo toxicities. However, one of the main obstacles that we have identified on the way to a potential clinical application as a treatment for malaria is the fast clearance of heparin from the circulation. The blood half-life of exogenously administered heparin is dependent on the dose, and it can be cleared slowly through the renal system 
or through a fast but saturable mechanism that involves binding to cell receptors and macrophages [37]. Depolymerization of the heparin chain has been described to increase circulation time because it reduces some of the undesired interactions with cell surfaces [43]. Conjugation to nanocarriers also has the potential to impart longer blood residence times [44], and there is evidence of loss of the anticoagulant activity of heparin when covalently immobilized on a substrate [45]. Several types of nanostructures have been used as such substrates, e.g., liposomes [18], polymersomes [46], and giant unilamellar vesicles [47]. Heparin has been shown to work as pRBC targeting element of liposomes loaded with antimalarial drugs, which added to its invasion blocking activity in a peculiar type of combination therapy [18]. Heparin itself has been directly conjugated to the highly hydrophobic antimalarial drug artesunate to form micellar nanostructures with improved pharmacokinetic profile [48].

Heparin has an affordable production cost and its purification from animal tissues does not need complicated protocols or costly equipment. The endogenous nature of heparin makes it highly biocompatible and biosafe, especially in the case of low molecular weight heparin, whose chemical preparation is simple and inexpensive. Among the various materials available to form nanocarriers, natural polymers such as glycosaminoglycans are an ideal candidate due to their often endogenous, non-immunogenic nature, ease of availability in relatively large amounts at a comparatively low cost, and presence in their structures of adequate chemical groups for the use of straightforward crosslinking reactions into nanoparticulate structures. Chitosan, a positively charged glycosaminoglycan, is being extensively employed as drug carrier in many clinical applications already and therefore its adaptation to the transport of antimalarial drugs would be immediate. Heparin, a glycosaminoglycan whose antimalarial activity is well known, could be easily incorporated into chitosan nanocarriers, since its high negative charge will provide a strong interaction with chitosan, which if required can be strengthened through a simple chemical reaction by covalent bonds between the abundant amino and carboxyl groups present in chitosan and heparin, respectively. Heparin has been described to have binding affinity for several Plasmodium stages, in both human and mosquito hosts, thus being an interesting targeting element of therapeutic nanovessels. In addition to the antiparasitic and targeting activities of heparin, such hybrid glycosaminoglycan nanovectors can be loaded with drugs, sky-rocketing their potential activity against the pathogen. As an added bonus of using chitosan nanoparticles is that they are inexpensive and easy to produce, and are apt to be used in oral therapy $[49,50]$.

Supplementary Materials: The following are available online at http://www.mdpi.com/1999-4923/12/9/825/s1, Figure S1: Partial ${ }^{1} \mathrm{H}$ NMR spectra of heparin and its modifications; Figure S2: Partial ${ }^{13} \mathrm{C}$ NMR spectra of heparin and its modifications; Figure S3: Partial ${ }^{13} \mathrm{C}$ NMR, HSQC, and TOCSY spectra of 2-O-desulfated MMWH; Figure S4: Partial HSQC and TOCSY spectra of 2-O-desulfated glycol-split MMWH_1; Figure S5: Partial HSQC and TOCSY spectra of 2-O-desulfated glycol-split MMWH_2; Figure S6: Partial HSQC and TOCSY spectra of 2-O-desulfated glycol-split ULMWH_1; Figure S7: Partial HSQC spectra of ULMWH; Figure S8: ${ }^{1} \mathrm{H}$ DOSY spectra of UH, MMWH, MMWH_1/2, ULMWH, and ULMWH_1.

Author Contributions: Conceptualization, X.F.-B.; methodology, E.L., C.R.A.-V., P.R., T.S. and X.F.-B.; investigation, E.L., C.R.A.-V. and P.R.; formal analysis, E.L.; visualization, E.L. and P.R.; writing-original draft preparation, X.F.-B. and E.L., writing-review and editing, X.F.-B. and E.L.; supervision, X.F.-B.; funding acquisition, X.F.-B, P.R. and T.S. All authors have read and agreed to the published version of the manuscript.

Funding: X.F.-B. received funding support from (i) the Spanish Ministry of Science, Innovation and Universities (http://www.ciencia.gob.es/), grant numbers BIO2014-52872-R and RTI2018-094579-B-I00 (which included FEDER funds), and (ii) BIOIBERICA. P.R. and T.S. received funding support from (i) the Spanish Ministry of Science, Innovation and Universities, grant number PGC2018-097583-B-I00 (which included FEDER funds), and (ii) Gobierno de Aragón-FEDER E47-20R. The authors would like to acknowledge the use of the Unidad de Apoyo a la Investigación del CEQMA, CSIC-Universidad de Zaragoza.

Acknowledgments: The authors would like to thank Miriam Ramírez for technical support, Lucía Román for assistance in liposomal preparation, and Fernando J. Pérez Asensio and the technical staff from the Animal Facility Service at the Barcelona Science Park for administrative and technical help. ISGlobal and IBEC are members of the CERCA Programme, Generalitat de Catalunya. We acknowledge support from the Spanish Ministry of Science, Innovation and Universities through the "Centro de Excelencia Severo Ochoa 2019-2023" Program (CEX2018-000806-S). This research is part of ISGlobal's Program on the Molecular Mechanisms of Malaria, which is partially supported by the Fundación Ramón Areces. 
Conflicts of Interest: X.F.-B. has received funding from BIOIBERICA, and C.R.A.-V. is employed by BIOIBERICA. The funders had no role in the design of the study; in the collection, analyses, or interpretation of data; in the writing of the manuscript, or in the decision to publish the results.

\section{References}

1. World Health Organization. World Malaria Report 2019; World Health Organization: Geneva, Switzerland, 2019.

2. Miller, L.H.; Baruch, D.I.; Marsh, K.; Doumbo, O.K. The pathogenic basis of malaria. Nature 2002, 415, 673-679. [CrossRef]

3. Carlson, J.; Wahlgren, M. Plasmodium falciparum erythrocyte rosetting is mediated by promiscuous lectin-like interactions. J. Exp. Med. 1992, 176, 1311-1317. [CrossRef] [PubMed]

4. Griffith, K.S.; Lewis, L.S.; Mali, S.; Parise, M.E. Treatment of malaria in the United States: A systematic review. JAMA 2007, 297, 2264-2277. [CrossRef] [PubMed]

5. Beeson, J.G.; Andrews, K.T.; Boyle, M.; Duffy, M.F.; Choong, E.K.; Byrne, T.J.; Chesson, J.M.; Lawson, A.M.; Chai, W. Structural basis for binding of Plasmodium falciparum erythrocyte membrane protein 1 to chondroitin sulfate and placental tissue and the influence of protein polymorphisms on binding specificity. J. Biol. Chem. 2007, 282, 22426-22436. [CrossRef]

6. Juillerat, A.; Igonet, S.; Vigan-Womas, I.; Guillotte, M.; Gangnard, S.; Faure, G.; Baron, B.; Raynal, B.; Mercereau-Puijalon, O.; Bentley, G.A. Biochemical and biophysical characterisation of DBL1a 1 -varO, the rosetting domain of PfEMP1 from the VarO line of Plasmodium falciparum. Mol. Biochem. Parasitol. 2010, 170, 84-92. [CrossRef] [PubMed]

7. Pradel, G.; Garapaty, S.; Frevert, U. Proteoglycans mediate malaria sporozoite targeting to the liver. Mol. Microbiol. 2002, 45, 637-651. [CrossRef]

8. Coppi, A.; Tewari, R.; Bishop, J.R.; Bennett, B.L.; Lawrence, R.; Esko, J.D.; Billker, O.; Sinnis, P. Heparan sulfate proteoglycans provide a signal to Plasmodium sporozoites to stop migrating and productively invade host cells. Cell Host Microbe 2007, 2, 316-327. [CrossRef] [PubMed]

9. Rogerson, S.J.; Reeder, J.C.; Al-Yaman, F.; Brown, G.V. Sulfated glycoconjugates as disrupters of Plasmodium falciparum erythrocyte rosettes. Am. J. Trop. Med. Hyg. 1994, 51, 198-203. [CrossRef]

10. Angeletti, D.; Sandalova, T.; Wahlgren, M.; Achour, A. Binding of subdomains 1/2 of PfEMP1-DBL1a to heparan sulfate or heparin mediates Plasmodium falciparum rosetting. PLoS ONE 2015, 10, e0118898. [CrossRef]

11. Vogt, A.M.; Pettersson, F.; Moll, K.; Jonsson, C.; Normark, J.; Ribacke, U.; Egwang, T.G.; Ekre, H.P.; Spillmann, D.; Chen, Q.; et al. Release of sequestered malaria parasites upon injection of a glycosaminoglycan. PLoS Pathog. 2006, 2, e100. [CrossRef]

12. Sheehy, T.W.; Reba, R.C. Complications of falciparum malaria and their treatment. Ann. Intern. Med. 1967, 66, 807-809. [CrossRef]

13. Leitgeb, A.M.; Blomqvist, K.; Cho-Ngwa, F.; Samje, M.; Nde, P.; Titanji, V.; Wahlgren, M. Low anticoagulant heparin disrupts Plasmodium falciparum rosettes in fresh clinical isolates. Am. J. Trop. Med. Hyg. 2011, 84, 390-396. [CrossRef]

14. Xiao, L.; Yang, C.; Patterson, P.S.; Udhayakumar, V.; Lal, A.A. Sulfated polyanions inhibit invasion of erythrocytes by plasmodial merozoites and cytoadherence of endothelial cells to parasitized erythrocytes. Infect. Immun. 1996, 64, 1373-1378. [CrossRef] [PubMed]

15. Boyle, M.J.; Richards, J.S.; Gilson, P.R.; Chai, W.; Beeson, J.G. Interactions with heparin-like molecules during erythrocyte invasion by Plasmodium falciparum merozoites. Blood 2010, 115, 4559-4568. [CrossRef] [PubMed]

16. Beeson, J.G.; Drew, D.R.; Boyle, M.J.; Feng, G.; Fowkes, F.J.I.; Richards, J.S. Merozoite surface proteins in red blood cell invasion, immunity and vaccines against malaria. FEMS Microbiol. Rev. 2016, 40, 343-372. [CrossRef] [PubMed]

17. Valle-Delgado, J.J.; Urbán, P.; Fernàndez-Busquets, X. Demonstration of specific binding of heparin to Plasmodium falciparum-infected vs. non-infected red blood cells by single-molecule force spectroscopy. Nanoscale 2013, 5, 3673-3680. [CrossRef] [PubMed]

18. Marques, J.; Moles, E.; Urbán, P.; Prohens, R.; Busquets, M.A.; Sevrin, C.; Grandfils, C.; Fernàndez-Busquets, X. Application of heparin as a dual agent with antimalarial and liposome targeting activities towards Plasmodium-infected red blood cells. Nanomed. NBM 2014, 10, 1719-1728. [CrossRef] 
19. Glushakova, S.; Busse, B.L.; Garten, M.; Beck, J.R.; Fairhurst, R.M.; Goldberg, D.E.; Zimmerberg, J. Exploitation of a newly-identified entry pathway into the malaria parasite-infected erythrocyte to inhibit parasite egress. Sci. Rep. 2017, 7, 12250. [CrossRef]

20. Boyle, M.J.; Skidmore, M.; Dickerman, B.; Cooper, L.; Devlin, A.; Yates, E.; Horrocks, P.; Freeman, C.; Chai, W.; Beeson, J.G. Identification of heparin modifications and polysaccharide inhibitors of Plasmodium falciparum merozoite invasion that have potential for novel drug development. Antimicrob. Agents Chemother. 2017, 61, e00709-e00717. [CrossRef] [PubMed]

21. Pisano, C.; Aulicino, C.; Vesci, L.; Casu, B.; Naggi, A.; Torri, G.; Ribatti, D.; Belleri, M.; Rusnati, M.; Presta, M. Undersulfated, low-molecular-weight glycol-split heparin as an antiangiogenic VEGF antagonist. Glycobiology 2005, 15, 1C-6C. [CrossRef]

22. Naggi, A.; Casu, B.; Perez, M.; Torri, G.; Cassinelli, G.; Penco, S.; Pisano, C.; Giannini, G.; Ishai-Michaeli, R.; Vlodavsky, I. Modulation of the heparanase-inhibiting activity of heparin through selective desulfation, graded $N$-acetylation, and glycol splitting. J. Biol. Chem. 2005, 280, 12103-12113. [CrossRef] [PubMed]

23. Shively, J.E.; Conrad, H.E. Formation of anhydrosugars in the chemical depolymerization of heparin. Biochemistry 1976, 15, 3932-3942. [CrossRef] [PubMed]

24. Cifonelli, J.A. Reaction of heparitin sulfate with nitrous acid. Carbohydr. Res. 1968, 8, 233-242. [CrossRef]

25. Matsuo, M.; Takano, R.; Kamei-Hayashi, K.; Hara, S. A novel regioselective desulfation of polysaccharide sulfates: Specific 6-O-desulfation with N,O-bis(trimethylsilyl)acetamide. Carbohydr. Res. 1993, 241, $209-215$. [CrossRef]

26. Maruyama, T.; Toida, T.; Imanari, T.; Yu, G.; Linhardt, R.J. Conformational changes and anticoagulant activity of chondroitin sulfate following its $O$-sulfonation. Carbohydr. Res. 1998, 306, 35-43. [CrossRef]

27. Casu, B.; Guerrini, M.; Naggi, A.; Perez, M.; Torri, G.; Ribatti, D.; Carminati, P.; Giannini, G.; Penco, S.; Pisano, C.; et al. Short heparin sequences spaced by glycol-split uronate residues are antagonists of fibroblast growth factor 2 and angiogenesis inhibitors. Biochemistry 2002, 41, 10519-10528. [CrossRef]

28. Bertini, S.; Bisio, A.; Torri, G.; Bensi, D.; Terbojevich, M. Molecular weight determination of heparin and dermatan sulfate by size exclusion chromatography with a triple detector array. Biomacromolecules 2005, 6, 168-173. [CrossRef]

29. Casu, B.; Gennaro, U. A conductimetric method for the determination of sulphate and carboxyl groups in heparin and other mucopolysaccharides. Carbohydr. Res. 1975, 39, 168-176. [CrossRef]

30. Gerotziafas, G.T.; Petropoulou, A.D.; Verdy, E.; Samama, M.M.; Elalamy, I. Effect of the anti-factor Xa and anti-factor Ila activities of low-molecular-weight heparins upon the phases of thrombin generation. J. Thromb. Haemost. 2007, 5, 955-962. [CrossRef]

31. Monakhova, Y.B.; Diehl, B.W.K.; Do, T.X.; Schulze, M.; Witzleben, S. Novel method for the determination of average molecular weight of natural polymers based on 2D DOSY NMR and chemometrics: Example of heparin. J. Pharm. Biomed. Anal. 2018, 149, 128-132. [CrossRef]

32. Lambros, C.; Vanderberg, J.P. Synchronization of Plasmodium falciparum erythrocytic stages in culture. J. Parasitol. 1979, 65, 418-420. [CrossRef]

33. Dluzewski, A.R.; Ling, I.T.; Rangachari, K.; Bates, P.A.; Wilson, R.J. A simple method for isolating viable mature parasites of Plasmodium falciparum from cultures. Trans. R. Soc. Trop. Med. Hyg. 1984, 78, 622-624. [CrossRef]

34. Fidock, D.A.; Rosenthal, P.J.; Croft, S.L.; Brun, R.; Nwaka, S. Antimalarial drug discovery: Efficacy models for compound screening. Nat. Rev. Drug Discov. 2004, 3, 509-520. [CrossRef] [PubMed]

35. Frazier, S.B.; Roodhouse, K.A.; Hourcade, D.E.; Zhang, L. The quantification of glycosaminoglycans: A comparison of HPLC, carbazole, and Alcian Blue methods. Open Glycosci. 2008, 1, 31-39. [CrossRef] [PubMed]

36. Warttinger, U.; Giese, C.; Harenberg, J.; Holmer, E.; Krämer, R. A fluorescent probe assay (Heparin Red) for direct detection of heparins in human plasma. Anal. Bioanal. Chem. 2016, 408, 8241-8251. [CrossRef] [PubMed]

37. Hirsh, J.; Fuster, V. Guide to anticoagulant therapy. Part 1: Heparin. Circulation 1994, 89, 1449-1468. [CrossRef] [PubMed] 
38. Esko, J.D.; Prestegard, H.; Linhardt, R.J. Proteins that bind sulfated glycosaminoglycans. In Essentials of Glycobiology, 3rd ed.; Varki, A., Cummings, R.D., Esko, J.D., Stanley, P., Hart, G.W., Aebi, M., Darvill, A.G., Kinoshita, T., Packer, N.H., Prestegard, J.H., et al., Eds.; Cold Spring Harbor Laboratory Press: Cold Spring Harbor, NY, USA, 2017; pp. 493-502.

39. Naggi, A. Glycol-splitting as a device for modulating inhibition of growth factors and heparanase by heparin and heparin derivatives. In Chemistry and Biology of Heparin and Heparan Sulfate; Garg, H.G., Linhardt, R.J., Hales, C.A., Eds.; Elsevier Science: Amsterdam, The Netherlands, 2005; pp. 461-481.

40. Allen, T.M.; Cullis, P.R. Liposomal drug delivery systems: From concept to clinical applications. Adv. Drug Deliv. Rev. 2013, 65, 36-48. [CrossRef]

41. Marques, J.; Vilanova, E.; Mourão, P.A.S.; Fernàndez-Busquets, X. Marine organism sulfated polysaccharides exhibiting significant antimalarial activity and inhibition of red blood cell invasion by Plasmodium. Sci. Rep. 2016, 6, 24368. [CrossRef]

42. Leitgeb, A.M.; Charunwatthana, P.; Rueangveerayut, R.; Uthaisin, C.; Silamut, K.; Chotivanich, K.; Sila, P.; Moll, K.; Lee, S.J.; Lindgren, M.; et al. Inhibition of merozoite invasion and transient de-sequestration by sevuparin in humans with Plasmodium falciparum malaria. PLoS ONE 2017, 12, e0188754. [CrossRef]

43. Hirsh, J.; Warkentin, T.E.; Shaughnessy, S.G.; Anand, S.S.; Halperin, J.L.; Raschke, R.; Granger, C.; Ohman, E.M.; Dalen, J.E. Heparin and low-molecular-weight heparin: Mechanisms of action, pharmacokinetics, dosing, monitoring, efficacy, and safety. Chest 2001, 119, 64S-94S. [CrossRef]

44. Mosqueira, V.C.F.; Loiseau, P.M.; Bories, C.; Legrand, P.; Devissaguet, J.P.; Barratt, G. Efficacy and pharmacokinetics of intravenous nanocapsule formulations of halofantrine in Plasmodium berghei-infected mice. Antimicrob. Agents Chemother. 2004, 48, 1222-1228. [CrossRef] [PubMed]

45. Miura, Y.; Aoyagi, S.; Kusada, Y.; Miyamoto, K. The characteristics of anticoagulation by covalently immobilized heparin. J. Biomed. Mater. Res. 1980, 14, 619-630. [CrossRef] [PubMed]

46. Najer, A.; Wu, D.; Bieri, A.; Brand, F.; Palivan, C.G.; Beck, H.P.; Meier, W. Nanomimics of host cell membranes block invasion and expose invasive malaria parasites. ACS Nano 2014, 8, 12560-12571. [CrossRef] [PubMed]

47. Najer, A.; Thamboo, S.; Palivan, C.G.; Beck, H.P.; Meier, W. Giant host red blood cell membrane mimicking polymersomes bind parasite proteins and malaria parasites. Chimia 2016, 70, 288-291. [CrossRef] [PubMed]

48. Ismail, M.; Du, Y.; Ling, L.; Li, X. Artesunate-heparin conjugate based nanocapsules with improved pharmacokinetics to combat malaria. Int. J. Pharm. 2019, 562, 162-171. [CrossRef]

49. Schulz, J.D.; Gauthier, M.A.; Leroux, J.C. Improving oral drug bioavailability with polycations? Eur. J. Pharm. Biopharm. 2015, 97, 427-437. [CrossRef]

50. Shukla, S.K.; Mishra, A.K.; Arotiba, O.A.; Mamba, B.B. Chitosan-based nanomaterials: A state-of-the-art review. Int. J. Biol. Macromol. 2013, 59, 46-58. [CrossRef]

(C) 2020 by the authors. Licensee MDPI, Basel, Switzerland. This article is an open access article distributed under the terms and conditions of the Creative Commons Attribution (CC BY) license (http://creativecommons.org/licenses/by/4.0/). 